Issue 2 (November, 2017)

\title{
Pengaruh Stres Kerja dan Pemberdayaan Terhadap Kepuasan Kerja Pegawai Pada Kantor Dinas Ketenagakerjaan Kota Makassar
}

\author{
Widyastuti Pertiwi M. ${ }^{1)}$, Herman Sjaharuddin²), Nurlaely Razak ${ }^{3)}$ \\ ${ }^{1)}$ Mahasiswa Program Studi Manajemen pada Sekolah Tinggi IImu Ekonomi Bongaya \\ Makassar \\ ${ }^{2,3)}$ Dosen Program Studi Manajemen pada Sekolah Tinggi Ilmu Ekonomi Bongaya \\ Makassar
}

\begin{abstract}
ABSTRAK
Penelitian ini bertujuan untuk menguji pengaruh stres kerja dan pemberdayaan terhadap kepuasan kerja pegawai pada Kantor Ketenagakerjaan Kota Makassar. Pengumpulan data menggunakan data primer yang diperoleh dari kuesioner dengan menggunakan teknik sampel jenuh. Poulasinya adalah seluruh pegawai tetap pada Kantor Dinas Ketenagakerjaan Kota Makassar berjumlah 68 pegawai tetap, dan sampel yang diambil berjumlah 68 responden. Hasil kuesioner tersebut telah diuji validitas dan reabilitasnya. Metode analisis data menggunakan teknik SEM (Sturctural equation modeling) dibantu dengan WarphPLS Ver.5.0). Hasil penelitian ini menunjukkan bahwa hipotesis stres kerja diterima karena menunjukkan hasil uji yang negatif dan signifikan. Ini berarti bahwa berpengaruh stres kerja negatif dan signifikan terhadap kepuasan kerja pegawai. Sedangkan hasil penelitian pada pemberdayaan menunjukkan bahwa hipotesis diterima karena menunjukkan hasil hipotesis yang positif dan signifikan. Ini berarti bahwa berpengaruh pemberdayaan positif dan signifikan terhadap kepuasan kerja pegawai.
\end{abstract}

Kata kunci : $\quad$ Stres Kerja, Pemberdayaan, Kepuasan Kerja

\begin{abstract}
This study aims to examine the influence of job stress and empowerment on job satisfaction at Dinas Ketenagakerjaan Kota Makassar. data collection using primary data obtained from questionnaires using saturated sampling technique. the population is all permanent employees of Kantor Dinas Ketenagakerjaan Kota Makassar number 68 employees, and the sample taken amounted to 68 respondents. the results of the questionnaire have been tested for validity and reliability. Data analysis method using SEM technique (struktural equation modeling) assisted by WarphPLS Ver.5.0). The result of this study indicate that the hypotesis of job stress is accepted because it shows the results of negative and significant hypothesis test. This means that the effect of negative and significant job stress on employee job satisfaction. While the results of research on empowerment shows that the hypothesis is accepted because it shows the results of a positive and significant hypothesis. This means that the effect of positive and significant empowerment on employee job satisfaction.
\end{abstract}

Keywords : job stress, empowerment, job satisfaction 
Issue 2 (November, 2017)

\section{A. Latar Belakang}

Kedudukan dan peranan Aparatur Sipil Negara yang bertugas sebagai abdi masyarakat untuk menyelenggarakan pelayanan secara adil kepada masyarakat dengan dilandasi kesetian dan ketaatan kepada Pancasila dan Undang-undang Dasar 1945. Untuk dapat melaksanakan tugas-tugas dengan baik, maka pembinaan ASN dalam sebuah instansi pemerintahan terutama pada Dinas Ketenagakerjaan Kota Makassar sangatlah penting untuk meningkatkan kualitas sumber daya manusia agar memilki sikap dan perilaku yang berintikan pengabdian, kejujuran, tanggung jawab, serta wibawa sehingga dapat memberikan pelayanan sesuai tuntutan perkembangan masyarakat (Effendy dan Sjahruddin, 2016).

Kepuasan kerja merupakan evaluasi yang menggambarkan seseorang atas perasaan sikapnya senang atau tidak senang, puas atau tidak puas dalam bekerja. (Tunjungsari, 2011, dalam Pratama dan Sriathi, 2015).

Berdasarkan teorinya, kepuasan kerja karyawan melalui Two Factor Theory. Berdasarkan teori X dan $Y$ yang dikemukakan oleh MC.Gregor dalam Hasibuan, (2008:160) bahwa teori pemeliharaan atau teori dua faktor $X$ dan $Y$ tentang motivasi, faktor tersebut dinamakan faktor $X$ yang membuat orang merasa tidak puas dan faktor $Y$ membuat orang merasa puas (faktor yang memotivasi orang). Faktor $\mathrm{X}$ memandang bahwa manusia itu adalah individu yang malas dalam melaksanakan pekerjaannya dan cenderung tidak merasakan kepuasan dalam bekerja terhadap apa yang telah diperolehnya sementara teori $Y$ memandang bahwa manusia itu adalah individu yang rajin dalam melaksanakan pekerjaannya dan merasakan kepuasan dalam bekerja terhadap apa yang telah diperolehnya. Kedua faktor tersebut dalam penelitian ini digunakan sebagai teori yang mendasari penciptaan pengaruh antar variabel, yaitu pengaruh stres kerja terhadap kepuasan kerja dan pemberdayaan terhadap kepuasan kerja. Teori tersebut menjelaskan bahwa tinggi ataupun rendahnya kepuasan kerja individu dipengaruhi oleh stres kerja dan pemberdayaan.

Teori tersebut menjelaskan bahwa tinggi ataupun rendahnya kepuasan kerja individu oleh dua faktor dalam penelitian ini disebutkan sebagai stres kerja dan pemberdayaan.

Stres kerja merupakan suatu kondisi yang terjadi ketika seseorang menyadari tekanan pada dirinya dan ketergantungan yang disebabkan oleh prasyarat pekerjaan(Rehman, dkk.,2012, dalam Widayanti dan Sariyathi, 2016). Indikator stres kerja dapat diukur melalui tuntutan tugas, tuntutan peran, tuntutan hubungan antarpribadi, struktur organisasi, kepemimpinan organisasi dan tahap hidup organisasi (Rahmawati, 2009 dalam Widayanti, dan Sariyathi, 2016). Bukti penelitian terdahulu menjelaskan bahwa stres kerja mempunyai pengaruh yang negatif dan signifikan terhadap kepuasan kerja yang dilakukan (Pratama, dan Sriathi,2015, dalam Widayanti, dan Sariyahti, 2016). Perbedaan hasil penelitian dalam menganalisis pengaruh stres kerja terhadap kepuasan kerja di tunjukkan oleh (Maqfiranti \& Sjahruddin, 2014) bahwa stres kerja berpengaruh positif dan tidak signifikan terhadap kinerja karyawan dimana kinerja sebagai cerminan dari kepuasan kerja.

Selain stres kerja faktor lain yang mempengaruhi kepuasan kerja yaitu pemberdayaan. Pemberdayaan adalah upaya memberikan otonomi, kepercayaan atasan kepada bawahan, serta mendorong mereka untuk kreatif agar dapat merampungkan tugasnya sebaik mungkin (Kadarisman, 2013:233, dalam Dewi dan Suwandana, 2016). Indikator pemberdayaan karyawan dapat diukur melalui meaning, competence, self-determination, impact(Kuo et al.,2010, dalam Widayanti dan Sariyathi, 2016). Berdasarkan hasil penelitian terdahulu yang dilakukan (Lodjo, 2013, dalam Pratama dan Sriathi, 2015)bahwa 
pemberdayaan berpengaruh dan tidak signifikan terhadap kepuasan kerja. Berbeda dengan hasil penelitian yang dilakukan oleh (Saputro, 2013) bahwa pemberdayaan sumber daya manusia berpengaruh secara parsial terhadap kinerja pegawai yang dicirikan melalui kepuasan kerja.

Berdasarkan hasil pengamatan lapangan terhadap kondisi stres kerja maka dari hasil wawancara dan fakta lapangan menunjukkan bahwa tingkat stres kerja pegawai disebabkan olehtingginya beban kerja pegawai dan beratnya sanksi yang diberikan. Kondisi yang menyerupai dengan permasalahan tersebut ditunjukkan melalui pemberdayaan dimana faktor pemberian pemberdayaan pegawai sesuai dengan kompetensi pegawai. Keberhasilan suatu organisasi dapat dilihat bukan hanya dari kinerja pegawai yang dihasilkan tetapi dapat juga dilihat dari kemampuan organisasi memberdayakan pegawainya. Kondisi lapangan menunjukkan bahwa tinggi dan rendahya kepuasan kerja pegawai berdasarkan hasil dari harapan dan kenyataan.Kepuasan kerja pegawai akan meningkat apabila diberikan kesempatan untuk dipromosikan secara adil.

\section{B. Tinjauan Pustaka}

\section{Pengertian Stres Kerja}

Stres kerja merupakan respon seseorang baik berupa emosi fisik dan kognitif (konseptual) terhadap situasi dari kapasitas tuntutan kerja yang tidak seimbang pada individu (Ardana, dkk, 2008:25 dalam Widayanti dan Sariyathi, 2016). Seseorang yang mengalami beban atau tugas yang berat tetapi ia tidak dapat mengatasi tugas yang telah dibebankan, maka tubuh akan merespon dengan tidak mampu menghadapi tugas tersebut (Wibowo, dkk. 2015 dalam Widayanti dan Sariyathi, 2016). Berdasarkan pendapat (Rahmawati, 2009, dalam Dewi dan Suwandana, 2016) maka indikator pengukuran stres kerja yang digunakan dalam penelitian ini antara lain: tuntutan tugas, tuntutan peran, tuntutan hubungan antarpribadi, struktur organisasi, kepemimpinan organisasi dan tahap hidup organisasi.

\section{Pengertian Pemberdayaan Karyawan}

Pemberdayaan adalah upaya memberikan otonomi, kepercayaan atasan kepada bawahan, serta mendorong mereka untuk kreatif agar dapat merampungkan tugasnya sebaik mungkin (Kadarisman, 2013:233, dalam Pratama dan Sriathi, 2015). Pemberdayaan karyawan merupakan pendekatan yang demokratis dimana pimpinan mendorong karyawan untuk ikut memutuskan dalam pengambilan keputusan yang bersangkutan dengan pekerjaan (Ismail, dkk., 2011, dalam Widayanti dan Sariyathi, 2016). Menurut pandangan lainnya menyangkut pemberdayaan karyawan menyatakan bahwa perusahaan yang melakukan pemberdayaan karyawan akan mampu meningkatkan tanggung jawab karyawan (Elnaga dan Imran, 2014, dalam Widayanti dan Sariyathi, 2016). Pemberdayaan diukur menggunakan beberapa indikator antara lain sebagai berikut (Kuo et al, 2010, dalam Widayanti dan Sariyathi, 2016): meaning, competence, self-determination, dan impact.

3. Kepuasan kerja

Kepuasan kerja merupakan evaluasi yang menggambarkan seseorang atas perasaan sikapnya senang atau tidak senang, puas atau tidak puas dalam bekerja (Tunjungsari, 2011, dalam Pratama dan Sriathi, 2015). Berdasarkan pendapat Robbins, (2010:149) maka indikator pengukuran kepuasan kerja antara lain: kepuasan dengan gaji, kepuasan dengan promosi, kepuasan dengan rekan kerja, 


\section{JURNAL ORGANISASI DAN MANAJEMEN}

Issue 2 (November, 2017)

kepuasan dengan atasan, dan kepuasan dengan pekerjaan itu sendiri. Teori kepuasan kerja mencoba mengungkapkan apa yang membuat sebagian orang lebih puas terhadap suatu pekerjaan daripada beberapa orang yang lain. Teori $X$ dan $Y$ yang dikemukakan oleh Mc.Gregor dalam Hasibuan (2008:160) bahwa teori pemeliharaan atau teori dua faktor $X$ dan $Y$ tentang motivasi, faktor tersebut dinamakan faktor $X$ yang membuat orang merasa tidak puas dan faktor $Y$ membuat orang merasa puas (faktor yang memotivasi orang). Kedua faktor tersebut dalam penelitian ini digunakan sebagai teori yang mendasari penciptaan pengaruh antar variabel, yaitu pengaruh stres kerja terhadap kepuasan kerja dan pemberdayaan terhadap kepuasan kerja. Teori tersebut menjelaskan bahwa tinggi ataupun rendahnya kepuasan kerja individu dipengaruhi oleh stres kerja dan pemberdayaan.

\section{Metode Penelitian}

Penelitian ini termasuk penelitian metode deskriptif kuantitatif yang bertujuan untuk menjelaskan suatu fenomena empiris yang disertai data statistik dan pola hubungan antara variabel. Pada penelitian ini variabel terikat kepuasan kerja $(Y)$ dipengaruhi oleh variabel bebas stres kerja $\left(\mathrm{X}_{1}\right)$ dan pemberdayaan pegawai $\left(\mathrm{X}_{2}\right)$. Penelitian ini menggunakan analisis SEM (Structural Equation Modeling dibantu dengan WarphPLS Ver. 5.0).

\section{Hasil Penelitian}

\section{Evaluasi Model Pengukuran (Outer Model) Model 1}

Evaluasi outer model dilakukan melalui 3 kriteria yaitu convergent validity, discriminant validity dan composite reliability. Berikut ini adalah hasil pengolahan data:

a. Convergent Validity (Validitas Konvergen)

Convergent validity dari model pengukuran dapat dilihat dari korelasi antara skor indikator dengan skor konstruknya (loading factor) dengan kriteria nilai loading factor dari setiap indikator lebih besar dari 0,70 dapat dikatakan valid. Selanjutnya untuk nilai $\mathrm{p}$-value apabila $<0,05$ dianggap signifikan. Loading faktor antara 0,40-0,70 harus tetap dipertimbangkan untuk dipertahankan. Selanjutnya dijelaskan pula bahwa, indikator dengan loading $<0,40$ dihapus dari model. Penghapusan indikator dengan loading antara 0,40-0,70 dilakukan apabila indikator tersebut dapat meningkatkan AVE dan composite reliability diatas nilai batasannya. Nilai batasan untuk AVE 0,50 dan composite reliability adalah 0,50 (Machfud dan Dwi, 2013: 66 dalam Arista, 2015). Hasil pengolahan Convergent Validity dapat dilihat pada tabel berikut ini: 
Tabel 4.1 Hasil output combined loadings and cross-loading (model 1)

\begin{tabular}{|c|c|c|c|c|c|c|}
\hline \multicolumn{7}{|c|}{${ }^{*}$ Combined loadings and cross-loadings * } \\
\hline Model 1 & Sk & Pmbryn & $\mathrm{Kp}$ & SE & $\begin{array}{c}\mathbf{P} \\
\text { value }\end{array}$ & Keterangan \\
\hline $\mathrm{X} 11$ & $(0.437)$ & -0.080 & -0.106 & 0.105 & $<0.001$ & $\begin{array}{l}\text { Tidak Memenuhi } \\
\text { convergent validity }\end{array}$ \\
\hline $\mathrm{X} 12$ & $(0.284)$ & -0.314 & 0.749 & 0.110 & 0.006 & $\begin{array}{l}\text { Tidak Memenuhi } \\
\text { convergent validity }\end{array}$ \\
\hline $\mathrm{X} 13$ & $(-0.539)$ & -0.236 & 0.433 & 0.102 & $<0.001$ & $\begin{array}{l}\text { Tidak Memenuhi } \\
\text { convergent validity }\end{array}$ \\
\hline $\mathrm{X} 14$ & $(0.550)$ & -0.143 & 0.268 & 0.101 & $<0.001$ & $\begin{array}{l}\text { Memenuhi } \\
\text { convergent validity }\end{array}$ \\
\hline $\mathrm{X} 15$ & $(0.812)$ & 0.318 & -0.298 & 0.093 & $<0.001$ & $\begin{array}{l}\text { Memenuhi } \\
\text { convergent validity }\end{array}$ \\
\hline $\mathrm{X} 16$ & $(0.838)$ & -0.218 & 0.191 & 0.092 & $<0.001$ & $\begin{array}{l}\text { Memenuhi } \\
\text { convergent validity }\end{array}$ \\
\hline $\mathrm{X} 21$ & 0.194 & $(0.875)$ & 0.174 & 0.091 & $<0.001$ & $\begin{array}{l}\text { Memenuhi } \\
\text { convergent validity }\end{array}$ \\
\hline X22 & -0.200 & $(0.897)$ & -0.121 & 0.090 & $<0.001$ & $\begin{array}{l}\text { Memenuhi } \\
\text { convergent validity }\end{array}$ \\
\hline $\mathrm{X} 23$ & 0.072 & $(0.682)$ & 0.630 & 0.097 & $<0.001$ & $\begin{array}{l}\text { Memenuhi } \\
\text { convergent validity }\end{array}$ \\
\hline $\mathrm{X} 24$ & -0.047 & $(0.850)$ & -0.557 & 0.092 & $<0.001$ & $\begin{array}{l}\text { Memenuhi } \\
\text { convergent validity }\end{array}$ \\
\hline Y11 & 0.065 & 0.330 & $(0.741)$ & 0.095 & $<0.001$ & $\begin{array}{l}\text { Memenuhi } \\
\text { convergent validity }\end{array}$ \\
\hline Y12 & 0.114 & -0.010 & $(0.778)$ & 0.094 & $<0.001$ & $\begin{array}{l}\text { Memenuhi } \\
\text { convergent validity }\end{array}$ \\
\hline Y13 & -0.259 & -0.269 & $(0.736)$ & 0.095 & $<0.001$ & $\begin{array}{l}\text { Memenuhi } \\
\text { convergent validity }\end{array}$ \\
\hline Y14 & -0.414 & -0.480 & $(0.665)$ & 0.097 & $<0.001$ & $\begin{array}{l}\text { Memenuhi } \\
\text { convergent validity }\end{array}$ \\
\hline Y15 & 0.478 & 0.408 & (0.688) & 0.097 & $<0.001$ & $\begin{array}{l}\text { Memenuhi } \\
\text { convergent validity }\end{array}$ \\
\hline
\end{tabular}

Sumber : Data Primer( diolah WarphPLS Ver 5.0, 2017)

Berdasarkan hasil pengolahan data diatas maka dapat dijelaskan bahwa Convergent validity (uji validitas) untuk konstruk Stres Kerja (X1) terdapat 3 indikator yang tidak memenuhi standart Convergent validity yaitu $\mathrm{X}_{11} \mathrm{X}_{12}$ dan $\mathrm{X}_{13}<0.70$, sehingga indikator tersebut harus dikeluarkan dari model, untuk indikator $\mathrm{X}_{14}$ tidak dikeluarkan dari model karena merunjuk pada pendapat (sofyan dan Heri, 2011: 18 dalam Hasanuddin,R., dan Sjaruddin , H. 2017) (Sofyan dan Heri, 2011: 18 dalam Hasanuddin, R., dan Sjahruddin, H. 2017) nilai standarized loading factor, diatas 0,5 dapat diterima, sedangkan dibawah 0,5 dikeluarkan dari model. Sehingga tidak ada alasan yang kuat untuk mengeluarkan indikator tersebut dan untuk indikator $\mathrm{X}_{15}$ dan $\mathrm{X}_{16}$ memenuhi standar Convergent Validity dengan nilai $>0.70$ dan $P$-value juga telah memenuhi syarat yaitu memiliki nilai sebesar $<0,001 \quad(<0,05)$ dalam semua indikator. Convergent validity (uji validitas) untuk konstruk pemberdayaan (X2) menunjukkan bahwa semua indikator tersebut telah memenuhi standar Convergent Validity dengan nilai $>0.70$ dan P-value juga telah memenuhi syarat yaitu memiliki nilai sebesar dan P- 


\section{JURNAL ORGANISASI DAN MANAJEMEN}

Issue 2 (November, 2017)

value juga telah memenuhi syarat yaitu memiliki nilai sebesar $<0,001$ $(<0,05)$ sehingga indikator-indikator tersebut tdk dikeluarkan pada model 2.

Convergent validity (uji validitas) untuk konstruk Kepuasan Kerja (Y) bahwa semua indikator tersebut memenuhi standar Convergent Validity dengan nilai $>0.70$ dan $P$-value juga telah memenuhi syarat yaitu memiliki nilai sebesar $<0,001(<0,05)$. Berdasarkan hasil tersebut ditemukan bahwa masih terdapat indikator dari variabel stres kerja (X1) yang tidak memenuhi standar Convergent Validity (uji validitas) yaitu, $\mathrm{X}_{11}, \mathrm{X} 1_{2}$, dan $\mathrm{X}_{13}$, dengan nilai sebesar $\mathrm{X}_{11}=0.473<0.70, \mathrm{X}_{12}=0.284<0.70$, dan $\mathrm{X}_{13}=0.539<0.70$, sehingga terdapat alasan yang cukup kuat untuk mengeluarkan dari model kemudian melanjutkannya pada model 2.

b. Uji Composite Reability

Penelitian ini menggunakan tiga variabel laten (variabel yang tidak terukur) yaitu variabel Stres kerja (X1) dan Pemberdayaan (X2) serta Kepuasan Kerja Pegawai (Y). Suatu variabel yang dipandang mampu (handal) dalam menjelaskan data dari variabe I tersebut, pengujiannya dapat dilihat pada nilai composite reliability dan Cronbach's Alpha > 0,60, untuk itu dapat diperlihatkan pada tabel berikut:

Tabel 2. Latent variable coefficients (composite reliability) (model 2)

\begin{tabular}{|c|c|c|c|}
\hline MODEL 1 & KI & PTI & KP \\
\hline R-Squared & & & 0,692 \\
\hline Composite reliab. & 0,600 & 0,898 & 0,845 \\
\hline Cronbach's Alpha & 0,442 & 0,846 & 0,770 \\
\hline Avg. Var. Extrac. & 0,371 & 0,690 & 0,522 \\
\hline Full Collin. VIF & 1,207 & 2,601 & 2,482 \\
\hline Q-Squared & & & 0,689 \\
\hline
\end{tabular}

Sumber : Data Primer (diolah WarphPLS Ver 5.0, 2017)

Nilai composite reliability untuk variabel stres kerja sebesar $0,600>0,60$ sedangkan untuk variabel pemberdayaan sebesar $0,898>0,60$ dan yang terakhir pada variabel kepuasan kerja pegawai sebesar 0,845 >0,60. Selanjutnya untuk Cronbach's Alpha pada variabel stres kerja sebesar 0,442 >0,60 sedangkan untuk variabel pemberdayaan sebesar 0,846 > 0,60 dan yang terakhir pada variabel kepuasan kerja pegawai sebesar 0,770 > 0,60 . Untuk nilai Average Variances Extracted (AVE)/ nilai variasi rata-rata pada variabel stres kerja sebesar $0,371>0,50$ sedangkan untuk variabel pemberdayaan sebesar $0,690<0,50$ dan yang terakhir pada variabel kepuasan kerja pegawai sebesar $0,522>0,50$.

Berdasarkan hasil tersebut maka nilai yang belum memenuhi kriteria pengujian, sehingga terdapat cukup alasan yang kuat untuk mengujinya kembali pada model 2 .

\section{Evaluasi Model Pengukuran (Outer Model) Model 2}

Pengolahan selanjutnya pada model 2 yaitu evaluasi outer model dilakukan melalui 3 kriteria yaitu convergent validity, discriminant validity dan composite reliability. Berikut ini adalah hasil pengolahan data:

a) Convergent Validity (validitas konvergen) 


\section{JURNAL ORGANISASI DAN MANAJEMEN}

Issue 2 (November, 2017)

Convergent validity dari model pengukuran dapat dilihat dari korelasi antara skor indikator dengan skor konstruknya (loading factor) dengan kriteria nilai loading factor dari setiap indikator lebih besar dari 0,70 dapat dikatakan valid. Selanjutnya untuk nilai $p$-value apabila $<0,05$ dianggap signifikan. Hasil pengolahan Convergent Validity dapat dilihat pada tabel berikut ini:

Tabel 3 Hasil output combined loadings and cross-loading

\begin{tabular}{|l|l|l|l|l|l|}
\hline \multicolumn{7}{|c|}{ Combined loadings and cross-loadings * } \\
\hline Model 2 & \multicolumn{1}{|c|}{ Sk } & \multicolumn{1}{|c|}{ Pmbryn } & \multicolumn{1}{c|}{ Kp } & SE & P value \\
\hline X14 & $(0.601)$ & -0.048 & 0.143 & 0.099 & $<0.001$ \\
\hline X15 & $(0.833)$ & 0.323 & -0.347 & 0.092 & $<0.001$ \\
\hline X16 & $(0.870)$ & -0.276 & 0.233 & 0.091 & $<0.001$ \\
\hline X21 & 0.216 & $(0.875)$ & 0.237 & 0.091 & $<0.001$ \\
\hline X22 & -0.221 & $(0.897)$ & -0.157 & 0.090 & $<0.001$ \\
\hline X23 & 0.121 & $(0.682)$ & 0.599 & 0.097 & $<0.001$ \\
\hline X24 & -0.087 & $(0.850)$ & -0.560 & 0.092 & $<0.001$ \\
\hline Y11 & 0.121 & 0.452 & $(0.741)$ & 0.095 & $<0.001$ \\
\hline Y12 & 0.137 & -0.019 & $(0.778)$ & 0.094 & $<0.001$ \\
\hline Y13 & -0.323 & -0.325 & 0.736 & 0.095 & $<0.001$ \\
\hline Y14 & -0.387 & -0.492 & 0.665 & 0.097 & $<0.001$ \\
\hline Y15 & 0.435 & 0.358 & 0.688 & 0.097 & $<0.001$ \\
\hline
\end{tabular}

Sumber : Data primer (diolah WarphPLS Ver 5.0, 2017)

Hasil pada tabel diatas, menunjukkan hasil pengujian Convergent Validity untuk model 2, dimana model 1 sebelumnya terdapat beberapa indikator pada variabel stres kerja yang tidak memenuhi standar Convergent Validity maka dilakukan pengujian model 2. Pada pengujian model 2 diatas, semua indikator yang tidak memenuhi standar Convergent Validity telah dikeluarkan dari model, sehingga pengujian Convergent Validity dalam model 2 telah memenuhi syarat yaitu memiliki nilai $>0.70$ dan P-value juga telah memenuhi syarat yaitu memiliki nilai sebesar $<0,001$ $(<0,05)$ untuk seluruh indikator dari variabel Stres kerja, Pemberdayaan dan Kepuasan kerja.

b) Discriminant validity (Validitas Diskriminan)

Discriminant validity dinilai dari cross loading pengukuran dengan konstruk. Dapat dilihat dengan melihat loading konstruk laten, yang akan memprediksi indikatornya lebih baik daripada konstruk lainnya. Jika korelasi konstruk dengan pokok pengukuran (setiap indikator) lebih besar daripada ukuran konstruk lainnya maka validitas diskriminan terpenuhi. 


\section{JURNAL ORGANISASI DAN MANAJEMEN}

Issue 2 (November, 2017)

Tabel 4.14 Nilai loading konstruk laten indikator ke konstruk lainnya

\begin{tabular}{|l|l|l|l|l|}
\hline \multirow{2}{*}{ Indikator } & \multicolumn{3}{|c|}{$\begin{array}{c}\text { Nilai Loading ke konstruk } \\
\text { lainnya }\end{array}$} & \multirow{2}{*}{ Keterangan } \\
\cline { 2 - 4 } & \multicolumn{1}{|c|}{ SK } & PMBDYN & \multicolumn{1}{|c|}{ KK } & \\
\hline X14 & $(0.601)$ & -0.048 & 0.143 & Terpenuhi \\
X15 & $(0.833)$ & 0.323 & -0.347 & Terpenuhi \\
X16 & $(0.870)$ & -0.276 & 0.233 & Terpenuhi \\
\hline X21 & 0.216 & $(0.875)$ & 0.237 & Terpenuhi \\
X22 & -0.221 & $(0.897)$ & -0.157 & Terpenuhi \\
X23 & 0.121 & $(0.682)$ & 0.559 & Terpenuhi \\
X24 & 0.087 & $(0.850)$ & -0.560 & Terpenuhi \\
\hline Y11 & 0.121 & 0.452 & $(0.741)$ & Terpenuhi \\
Y12 & 0.137 & -0.019 & $(0.778)$ & Terpenuhi \\
Y13 & 0.323 & -0.325 & $(0.736)$ & Terpenuhi \\
Y14 & -0.387 & -0.492 & $(0.665)$ & Terpenuhi \\
Y15 & 0.435 & 0.358 & $(0.688)$ & Terpenuhi \\
\hline
\end{tabular}

Sumber: Data primer (diolah WarphPLS Ver 5.0, 2017)

Berdasarkan data di atas, keseluruhan indikator telah memenuhi kriteria validitas diskriminan. Variabel stres kerja yang memiliki 3 indikator yang dilambangkan dengan $\mathrm{X}_{14}, \mathrm{X}_{15}$ dan $\mathrm{X}_{16}$. Untuk indikator $\mathrm{X}_{15}$ memiliki nilai loading 0,833 yang nilai loading-nya lebih besar dari loading ke konstruk lain yaitu 0,323 dan $-0,347$ dan ke 3 indikator karakteristik individu lainnya juga memiliki nilai loading yang lebih besar dari nilai loading ke konstruk lain.

Variabel pemberdayaan yang memiliki 4 indikator yang dilambangkan dengan $\mathrm{X}_{21}, \mathrm{X}_{22}, \mathrm{X}_{23}$ dan $\mathrm{X}_{24}$. Untuk indikator $\mathrm{X}_{23}$ memiliki nilai loading 0,682 yang nilai loading-nya lebih besar dari loading ke konstruk lain yaitu 0,121 dan 0,559 dan ke 3 indikator pemberdayaan lainnya juga memiliki nilai loading yang lebih besar dari nilai loading ke konstruk lain.

Variabel kepuasan kerja yang memiliki 5 indikator yang dilambangkan dengan $Y_{11}, Y_{12}, Y_{13}, Y_{14}$ dan $X_{15}$. Untuk indikator $X$ memiliki nilai loading 0,668 yang nilai loading-nya lebih besar dari loading ke konstruk lain yaitu 0,435 dan 0,358 dan ke 2 indikator pemanfaatan teknologi informasi lainnya juga memiliki nilai loading yang lebih besar dari nilai loading ke konstruk lain. Berdasarkan uraian tersebut, dapat disimpulkan bahwa keseluruhan indikator telah memenuhi kriteria validitas diskriminan.

c) Uji Composite Reliability (Uji reliabilitas konstruk)

Suatu variabel yang dipandang mampu (handal) dalam menjelaskan data dari variabel tersebut, pengujiannya dapat dilihat pada nilai composite reliability dan Cronbach's Alpha < 0,60 , untuk itu dapat diperlihatkan pada tabel berikut: 
Tabel 4.11 Hasil output latent variable coefficients (model 2)

\begin{tabular}{|c|c|c|c|}
\hline MODEL 2 & KI & PTI & KP \\
\hline R-Squared & & & 0,723 \\
\hline Composite reliab. & 0,817 & 0,898 & 0,715 \\
\hline Cronbach's Alpha & 0,661 & 0,846 & 0,770 \\
\hline Avg. Var. Extrac. & 0,604 & 0,690 & 0,522 \\
\hline Full Collin. VIF & 1,168 & 2,575 & 2,480 \\
\hline Q-Squared & & & 0,718 \\
\hline
\end{tabular}

Sumber: Data primer (diolah WarphPLS Ver 5.0, 2017)

Nilai composite reliability untuk variabel stres kerja sebesar 0,817 $>0,60$ sedangkan untuk variabel pemberdayaan sebesar 0,898 $>0,60$ dan yang terakhir pada variabel kepuasan kerja sebesar 0,715 $>0,60$. Selanjutnya untuk Cronbach's Alpha pada variabel stres kerja sebesar $0,661>0,60$ sedangkan untuk variabel pemberdayaan sebesar $0,846>$ 0,60 dan yang terakhir pada variabel kepuasan kerja sebesar $0,770>$ 0,60 . Untuk nilai Average Variances Extracted (AVE)/ nilai variasi ratarata pada variabel stres kerja sebesar 0,604 > 0,50 sedangkan untuk variabel pemberdayaan sebesar $0,690<0,50$ dan yang terakhir pada variabel kepuasan kerja sebesar 0,522 >0,50.

Berdasarkan hasil tersebut maka keseluruhan nilai memenuhi kriteria pengujian, sehingga dapat dijelaskan pada tabel sebagai berikut :

Tabel 4.12 Nilai AVE (Average Variance Extracted) (model 2)

\begin{tabular}{|l|l|l|l|}
\hline \multicolumn{4}{|l|}{ Average Variance Extracted (AVE) } \\
\hline Variabel Laten & Nilai AVE & Kriteria & Keterangan \\
\hline SK & 0,604 & $>0,50$ & $\begin{array}{l}\text { Memenuhi convergent } \\
\text { validity }\end{array}$ \\
\hline PMBYN & 0,690 & $>0,50$ & $\begin{array}{l}\text { Memenuhi convergent } \\
\text { validity }\end{array}$ \\
\hline KP & 0,522 & $>0,50$ & $\begin{array}{l}\text { Memenuhi convergent } \\
\text { validity }\end{array}$ \\
\hline
\end{tabular}

Sumber: Data primer (diolah WarphPLS Ver 5.0, 2017)

Berdasarkan hasil tersebut ketiga konstruk telah memenuhi convergent validity. Stres kerja dengan nilai 0,604 >0,50, Pemberdayaan dengan nilai 0,690 juga telah memenuhi nilai $>0,50$ dan Kepuasan kerja memiliki nilai $0,522>0,50$. Kesimpulannya keseluruhan variabel telah memenuhi kriteria convergent validity.

Selanjutnya analisis mengenai standard error, yang dituliskan dengan huruf SE. Semakin kecil standard error dari suatu indikator maka semakin baik atau semakin layak. Standard error yang besar menunjukkan adanya ketidaklayakan model yang disusun, dan diharapkan nilainya relatif kecil yaitu dibawah 0,5 atau 0,4 dan tidak boleh bernilai negatif (Konsultan Statistik, 2009, dalam Arista, 2015). Berikut ini disajikan dalam tabel untuk masing-masing indikator: 
Tabel 6 Hasil Standard Error

\begin{tabular}{|l|l|l|l|}
\hline Indikator & $\begin{array}{c}\text { SE } \\
\text { Standar } \\
\boldsymbol{d} \text { Error) }\end{array}$ & \multicolumn{1}{|c|}{ Kriteria } & \multicolumn{1}{|c|}{ Keterangan } \\
\hline $\mathbf{X}_{\mathbf{1 4}}$ & 0.099 & $\begin{array}{l}<0,5 \text { atau }<0,4 \text { dan } \\
\text { tidak negatif }\end{array}$ & $\begin{array}{l}\text { Memenuhi kelayakan } \\
\text { model }\end{array}$ \\
\hline $\mathbf{X}_{\mathbf{1 5}}$ & 0.092 & $\begin{array}{l}<0,5 \text { atau }<0,4 \text { dan } \\
\text { tidak negatif }\end{array}$ & $\begin{array}{l}\text { Memenuhi kelayakan } \\
\text { model }\end{array}$ \\
\hline $\mathbf{X}_{\mathbf{1 6}}$ & 0.091 & $\begin{array}{l}<0,5 \text { atau }<0,4 \text { dan } \\
\text { tidak negatif }\end{array}$ & $\begin{array}{l}\text { Memenuhi kelayakan } \\
\text { model }\end{array}$ \\
\hline $\mathbf{X}_{\mathbf{2 1}}$ & 0.091 & $\begin{array}{l}<0,5 \text { atau }<0,4 \text { dan } \\
\text { tidak negatif }\end{array}$ & $\begin{array}{l}\text { Memenuhi kelayakan } \\
\text { model }\end{array}$ \\
\hline $\mathbf{X}_{\mathbf{2 2}}$ & 0.090 & $\begin{array}{l}<0,5 \text { atau }<0,4 \text { dan } \\
\text { tidak negatif }\end{array}$ & $\begin{array}{l}\text { Memenuhi kelayakan } \\
\text { model }\end{array}$ \\
\hline $\mathbf{X}_{\mathbf{2 3}}$ & 0.097 & $\begin{array}{l}<0,5 \text { atau }<0,4 \text { dan } \\
\text { tidak negatif }\end{array}$ & $\begin{array}{l}\text { Memenuhi kelayakan } \\
\text { model }\end{array}$ \\
\hline $\mathbf{X}_{\mathbf{2 4}}$ & 0.092 & $\begin{array}{l}<0,5 \text { atau }<0,4 \text { dan } \\
\text { tidak negatif }\end{array}$ & $\begin{array}{l}\text { Memenuhi kelayakan } \\
\text { model }\end{array}$ \\
\hline $\mathbf{Y}_{11}$ & 0.095 & $\begin{array}{l}<0,5 \text { atau }<0,4 \text { dan } \\
\text { tidak negatif }\end{array}$ & $\begin{array}{l}\text { Memenuhi kelayakan } \\
\text { model }\end{array}$ \\
\hline $\mathbf{Y}_{\mathbf{1 2}}$ & 0.094 & $\begin{array}{l}<0,5 \text { atau }<0,4 \text { dan } \\
\text { tidak negatif }\end{array}$ & $\begin{array}{l}\text { Memenuhi kelayakan } \\
\text { model }\end{array}$ \\
\hline $\mathbf{Y}_{\mathbf{1 3}}$ & 0.095 & $\begin{array}{l}<0,5 \text { atau }<0,4 \text { dan } \\
\text { tidak negatif }\end{array}$ & $\begin{array}{l}\text { Memenuhi kelayakan } \\
\text { model }\end{array}$ \\
\hline $\mathbf{Y}_{\mathbf{1 4}}$ & 0.097 & $\begin{array}{l}<0,5 \text { atau }<0,4 \text { dan } \\
\text { tidak negatif }\end{array}$ & $\begin{array}{l}\text { Memenuhi kelayakan } \\
\text { model }\end{array}$ \\
\hline $\mathbf{Y}_{\mathbf{1 5}}$ & 0.097 & $\begin{array}{l}<0,5 \text { atau }<0,4 \text { dan } \\
\text { tidak negatif }\end{array}$ & $\begin{array}{l}\text { Memenuhi kelayakan } \\
\text { model }\end{array}$ \\
\hline
\end{tabular}

Sumber: Data primer (diolah WarphPLS Ver 5.0, 2017)

Berdasarkan tabel di atas, dapat disimpulkan bahwa keseluruhan indikator memiliki kelayakan model. Variabel stres kerja (SK), pemberdayaan (PMBDYN) dan kepuasan kerja (KP) memilki nilai standard error yang sesuai kriteria yaitu $<0,5$ dan dianggap layak.

\section{Evaluasi Model Struktural (Inner ModeI)}

Tahap selanjutnya adalah melakukan evaluasi struktural (inner model) yang meliputi uji kecocokan model (model fit), path coefficient, dan $R^{2}$. Pada uji kecocokan model terdapat 3 indeks pengujian, yaitu average path coefficient (APC), average $R$-squared (ARS) dan average varians factor (AVIF) dengan kriteria APC dan ARS diterima dengan syarat $p-$ value $<0,05$ dan AVIF lebih kecil dari 5 (Mahfud Sholihin dan Dwi Ratmono, 2013: 61). Berikut ini adalah hasil output fit indices yang disajikan dalam bentuk tabel yaitu: 
Tabel 7. Hasil output model fit indices

\begin{tabular}{|c|l|l|l|l|}
\hline \multicolumn{1}{|c|}{ Indeks } & \multicolumn{1}{c|}{$\boldsymbol{P}$-Value } & \multicolumn{1}{c|}{ Kriteria } & Keterangan \\
\hline APC & 0,498 & $\mathrm{P}<0,001$ & $\mathrm{P}<0,05$ & Diterima \\
\hline ARS & 0,723 & $\mathrm{P}<0,001$ & $\mathrm{P}<0,05$ & Diterima \\
\hline AVIF & $\begin{array}{l}1,127 \text { Acceptable if } \\
<5\end{array}$ & & $\mathrm{AVIF}<5$ & Diterima \\
\hline
\end{tabular}

Sumber : Data primer (diolah WarphPLS Ver 5.0, 2017)

Hasil output di atas, menjelaskan bahwa APC memiliki indeks sebesar 0,498 dengan nilai $p-$ value $<0,001$. Sedangkan ARS memiliki indeks sebesar 0,723 dengan $p-$ value $<0,001$. Berdasarkan kriteria, APC sudah memenuhi kriteria karena memiliki nilai $p<0,001$. Begitu pula dengan nilai $p$ dari ARS yaitu $p<0,001$. Nilai AVIF yang harus $<5$ sudah terpenuhi karena berdasarkan data tersebut AVIF nilainya 1,127. Dengan demikian, maka inner model dapat diterima.

\section{a. Hasil Uji Hipotesis}

Penelitian atau hipotesis. Hasil korelasi antar konstruk diukur dengan melihat path coefficients dan tingkat signifikansinya yang kemudian dibandingkan dengan hipotesis penelitian yang terdapat di bab dua. Tingkat signifikansi yang dipakai dalam penelitian ini adalah sebesar $5 \%$. Berikut ini hipotesis yang dimaksudkan untuk membuktikan kebenaran dugaan penelitian yang terdiri dari tiga hipotesis, yaitu:

$\mathrm{H}_{1}=\quad$ Stres Kerja berpengaruh negatif dan signifikan terhadap kepuasan kerja pegawai pada Kantor Dinas Ketenagakerjaan Kota Makassar.

$\mathrm{H}_{2}=$ Pemberdayaan berpengaruh positif dan signifikan terhadap kepuasan kerja pegawai pada Kantor Dinas Ketenagakerjaan Kota Makassar.

$\mathrm{H}_{3}=$ Pemberdayaan dominan berpengaruh positif dan signifikan terhadap kepuasan kerja pegawai pada Kantor Dinas Ketenagakerjaan Kota Makassar.

Berikut ini merupakan gambaran hasil penelitian yang telah diperoleh berdasarkan pengolahan data : 
Gambar 1 Hasil penelitian

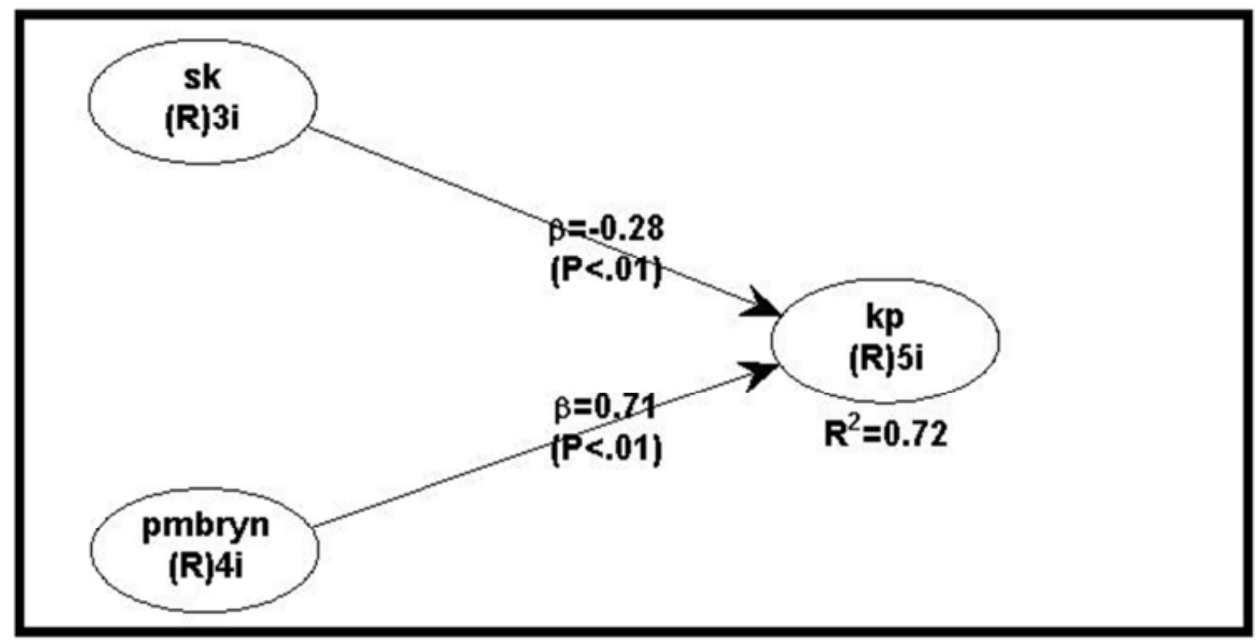

Sumber: Data primer (diolah WarphPLS Ver 5.0, 2017)

Keterangan gambar : SK

Pmbdyn

KK
: Stres Kerja

: Pemberdayaan

: Kepuasan Kerja

Berikut ini tabel hasil pengujian hipotesis yang telah diperoleh berdasarkan pengolahan data

Tabel 8 Pengujian Hipotesis (model 2)

\begin{tabular}{|l|l|l|l|l|}
\hline Kriteria & Variabel & Sk & Pbdyn & Kk \\
\hline Path coefficients & Sk & - & - & - \\
\cline { 2 - 5 } & Pbdyn & - & - & - \\
\cline { 2 - 5 } & Kk & -0.282 & 0.713 & - \\
\hline \multirow{4}{*}{$p$-values } & Sk & - & - & - \\
\cline { 2 - 5 } & Pbdyn & - & - & - \\
\cline { 2 - 5 } & Kk & 0.006 & 0.001 & - \\
\hline \multirow{2}{*}{$\begin{array}{l}\text { Effect size for } \\
\text { path }\end{array}$} & Sk & - & - & - \\
\cline { 2 - 5 } & Pbdyn & - & - & - \\
\cline { 2 - 5 } & Kk & 0.147 & 0.576 & - \\
\hline
\end{tabular}

Sumber : Data primer (diolah WarphPLS Ver 5.0, 2017)

Hasil output di atas, menjelaskan bahwa path coefficients untuk variabel stres kerja terhadap kepuasan kerja memiliki indeks sebesar 0,282 dengan nilai $p-$ value $<0,001$ dan nilai effect size for path 0,147 sedangkan untuk path coefficients variabel pemanfaatan teknologi informasi terhadap kinerja pegawai memiliki indeks sebesar 0,713 dengan $p$-value 0,001 nilai effect size for path 0,147.

Setelah melakukan uji hipotesis, berikut ini tabel yang merangkum uji hipotesis-hipotesis tersebut : 
Issue 2 (November, 2017)

Tabel 9 hasil uji hipotesis

\begin{tabular}{|l|l|l|l|l|}
\hline Hipotesis & \multicolumn{1}{|c|}{ Independen } & \multicolumn{1}{c|}{ Dependen } & p-values & Keputusan \\
\hline $\mathrm{H}_{1}$ & Kepuasan kerja & Stres kerja & 0.006 & Diterima \\
\hline $\mathrm{H}_{2}$ & Kepuasan kerja & Pemberdayaan & 0.001 & Dterima \\
\hline $\mathrm{H}_{3}$ & Kepuasan kerja & Stres kerja dan & Nilai & Diterima \\
& & Pemberdayaan & 0.147 dari & \\
& & & nilai 0.576 & \\
\hline
\end{tabular}

Sumber : Data primer (diolah WarphPLS Ver 5.0, 2017)

Berdasarkan tabel hasil uji hipotesis diatas, dapat diperoleh :

1. Uji hipotesis 1 diterima, artinya variabel stres kerja memiliki pengaruh negatif dan signifikan terhadap kepuasan kerja terhadap kepuasan kerja pegawai pada kantor dinas ketenagakerjaan kota makassar. Hal ini ditunjukkan dengan nilai beta $(\beta)$ sebesar 0,147 dengan nilai $p$ value $<0.006$.

2. Uji hipotesis 2 diterima, artinya variabel pemberdayaan memiliki pengaruh positif dan signifikan terhadap kepuasan kerja pegawai pada kantor dinas ketenagakerjaan kota makassar. Hal ini ditunjukkan dengan nilai beta $(\beta)$ sebesar 0,576 dengan nilai $p$-value 0,001 .

3. Uji hipotesis 3 diterima, artinya variabel pemberdayaan dominan memiliki pengaruh positif dan signifikan terhadap kepuasan kerja pegawai pada Kantor Dinas Ketenagakerjaan Kota Makassar. Hal ini ditunjukkan dengan variabel pemberdayaan memiliki nilai lebih tinggi yaitu nilai beta $(\beta)$ sebesar 0,576 dengan nilai $p$-value $<0.001$ dibandingkan dengan variabel stres kerja dengan nilai beta $(\beta)$ sebesar 0,147 dan nilai $p$-value 0,006 .

\section{b. Uji besaran pengaruh variabel independen terhadap variabel dependen}

Pengujian besaran pengaruh variabel independen terhadap variabel dependen dapat ditunjukkan pada tabel berikut :

Tabel 10 Ringkasan model (model summary)

\begin{tabular}{|l|c|c|c|}
\hline \multicolumn{1}{|c|}{ MODEL 2 } & SK & PMBDYN & KK \\
\hline R-squared & & & 0.723 \\
\hline Adj. R-squared & & & 0.715 \\
\hline Composite reliab. & 0.817 & 0.898 & 0.845 \\
\hline Cronbach's Alpha & 0.661 & 0.846 & 0.770 \\
\hline Avg. Var. Extrac. & 0.604 & 0.690 & 0.522 \\
\hline
\end{tabular}

Sumber: Data primer (diolah WarphPLS Ver 5.0, 2017)

Berdasarkan tabel diatas besaran pengaruh nilai $R$-squared pada variabel stres kerja dan variabel pemberdayaan terhadap kepuasan kerja adalah $0,723(72,3 \%)$ dan sisanya $27,7 \%$ dipengaruhi oleh variabel lain yang tidak dianalisis dalam penelitian ini seperti motivasi kerja, disiplin kerja, dan variabel lainnya. 


\section{JURNAL ORGANISASI DAN MANAJEMEN}

Issue 2 (November, 2017)

\section{a. Pengaruh stres kerja terhadap kepuasan kerja}

Berdasarkan hasil penelitian, ditemukan bahwa stres kerja memiliki pengaruh terhadap kepuasan kerja. Hasil ini sama dengan teori atau temuan dalam penelitian sebelumnya oleh Pratama \& Sriathi, (2015) memberikan bukti bahwa stres kerja berpengaruh negatif dan signifikan terhadap kepuasan kerja pegawai.

Dalam penelitian ini dapat dilihat dari nilai koefisien beta yang menunjukkan bahwa semakin tinggi stres kerja maka semakin rendah pula tingkat kepuasan kerja pegawai yaitu dengan nilai beta $(\beta)$ sebesar 0,147 .

Hal ini menunjukkan bahwa variabel stres kerja dapat mempengaruhi tingkat kepuasan kerja pegawai kearah yang negatif. Penyebab negatif dan signifikannya pengaruh stres kerja terhadap kepuasan kerja diakibatkan karena pegawai yang merasakan stres dalam bekerja tidak mampu mengimbangi tugas yang diberikan sehingga pegawai tidak akan merasa puas dengan pekerjaannya. Kondisi tersebut didukung dengan pegawai yang memiliki kemampuan dan pemahaman yang tinggi terhadap pekerjaannya sehingga tugas yang diberikan dapat terselesaikan secara tepat waktu sehingga berdampak nyata terhadap tuntutan pekerjaan untuk dapat diselesaikan dengan cepat dan sesuai dengan standar kerja yang ditetapkan pada Kantor Dinas Ketenagakerjaan Kota Makassar.

b. Pengaruh Pemberdayaan terhadap kepuasan kerja pegawai

Berdasarkan hasil penelitian, ditemukan bahwa pemberdayaan memiliki pengaruh terhadap kepuasan kerja pegawai. Hasil ini sama dengan teori atau temuan dalam penelitian sebelumnya oleh Pratama dan Sriathi, (2015) bahwa Pemberdayaan berpengaruh positif dan signifikan terhadap Kepuasan kerja.

Dalam penelitian ini dapat dilihat dari nilai koefisien beta yang menunjukkan bahwa pemberdayaan memiliki pengaruh positif dan signifikan terhadap kepuasan kerja pegawai yaitu dengan nilai beta $(\beta)$ sebesar 0,576 .

Hal ini menunjukkan bahwa variabel pemberdayaan mampu memengaruhi tingkat kepuasan kerja pegawai. Penyebab positif dan signifikannya pengaruh pemberdayaan diakibatkan karena pegawai dalam menyelesaikan pekerjaan mendapatkan dukungan dari atasannya sehingga pegawai mampu menyelesaikan pekerjaannya dengan baik dan tepat waktu yang disebabkan karena loyalitas kerja yang tinggi terhadap instansi dan rekan kerja sehingga berdampak nyata terhadap tuntutan agar pekerjaan terselesaikan dengan tepat waktu sehingga tidak menimbulkan permasalahan yang menghambat pegawai dalam menyelesaikan pekerjaannya. Kondisi tersebut didukung dengan komunikasi pegawai dengan atasan terjalin dengan baik dalam menyelesaikan masalah pekerjaan yang terdapat pada Kantor Dinas Ketenagakerjaan Kota Makassar.

c. Pengaruh Pemberdayaan Dominan Dibandingkan Dengan stres kerja Terhadap Kepuasan kerja Pegawai

Berdasarkan hasil penelitian, ditemukan bahwa pengaruh pemberdayaan lebih dominan dibandingkan pengaruh stres kerja terhadap kepuasan kerja pegawai.

Hasil tersebut dalam penelitian ini dapat dilihat dari nilai koefisien beta yang ditunjukkan pemberdayaan lebih tinggi yaitu dengan nilai beta 


\section{JURNAL ORGANISASI DAN MANAJEMEN}

Issue 2 (November, 2017)

( $\beta$ ) sebesar 0,576 dan nilai koefisien beta yang ditunjukkan oleh stres kerja yaitu dengan nilai 0,147.

Hal ini menunjukkan bahwa variabel pemberdayaan dapat memengaruhi tingkat kepuasan kerja pegawai kearah yang lebih tinggi dibandingkan variabel stres kerja. Penyebab positif dan signifikannya dominan pengaruh pemberdayaan terhadap kepuasan kerja pegawai diakibatkan karena pegawai dalam bekerja mendapatkan dukungan dari atasannya dalam menyelesaikan pekerjaannya sehingga berdampak pada komunikasi pegawai dengan atasan terjalin dengan baik dalam menyelesaikan masalah pekerjaan yang terdapat pada Kantor Dinas Ketenagakerjaan Kota Makassar.

Kondisi tersebut didukung dengan menjaga rasa saling membantu dan menghargai terhadap sesama rekan kerja dan menunjukkan loyalitas kerja yang tinggi terhadap instansi dan rekan kerja sehingga berdampak nyata terhadap tuntutan agar pekerjaan terselesaikan dengan tepat waktu sehingga tidak menimbulkan permasalahan yang menghambat pegawai dalam menyelesaikan pekerjaannya pada Kantor

\section{Kesimpulan}

Dinas Ketenagakerjaan Kota Makassar.

Stres kerja berpengaruh negatif dan signifikan terhadap kepuasan kerja pegawai. Kondisi tersebut disebabkan karena stres kerja dapat mempengaruhi tingkat kepuasan kerja pegawai kearah yang lebih rendah. Penyebab negatif dan signifikannya pengaruh stres kerja terhadap kepuasan diakibatkan karena pegawai yang merasakan stres dalam bekerja tidak mampu mengimbangi tugas yang diberikan sehingga pegawai tidak akan merasa puas dengan pekerjaannya. Kondisi tersebut didukung dengan pegawai yang memiliki kemampuan dan pemahaman yang tinggi terhadap pekerjaannya sehingga tugas yang diberikan dapat terselesaikan secara tepat waktu sehingga berdampak nyata terhadap tuntutan pekerjaan untuk dapat diselesaikan dengan cepat dan sesuai dengan standar kerja yang ditetapkan pada Kantor Dinas Ketenagakerjaan Kota Makassar. Pemberdayaan berpengaruh positif dan signifikan terhadap kepuasan kerja pegawai.

Penyebab positif dan signifikannya disebabkan karena pegawai dalam menyelesaikan pekerjaannya mendapatkan dukungan dari atasannya sehingga pegawai mampu menyelesaikan pekerjaannya dengan baik dan tepat waktu. Kondisi tersebut didukung dengan komunikasi pegawai dengan atasan terjalin dengan baik dalam menyelesaikan masalah pekerjaan yang terdapat pada Kantor Dinas Ketenagakerjaan Kota Makassar. Pemberdayaan dominan berpengaruh dibandingkan stres kerja terhadap kepuasan kerja. Kondisi tersebut disebabkan karena variable pemberdayaan dapat mempengaruhi peningkatan kepuasan kerja pegawai dibandingkat variable stres kerja. Penyebab positif dan signifikannya dominan pengaruh pemberdayaan terhadap kepuasan diakibatkan karena $p$ egawai dalam bekerja mendapatkan dukungan dari atasannya dalam menyelesaikan pekerjaannya sehingga berdampak nyata terhadap tuntutan agar pekerjaan terselesaikan dengan tepat waktu sehingga tidak menimbulkan permasalahan yang menghambat pegawai dalam menyelesaikan pekerjaannya pada Kantor Dinas Ketenagakerjaan Kota Makassar.

Disarankan kepada peneliti lanjutan agar objek penelitian sebaiknya diperluas, sehingga hasil yang diperoleh lebih maksimal 


\section{JURNAL ORGANISASI DAN MANAJEMEN}

Issue 2 (November, 2017)

\section{DAFTAR PUSTAKA}

Arifin, A. (2014). Pengaruh Pemberdayaan Dan Motivasi Terhadap Kinerja Karyawan (Studi pada Karyawan CV. Catur Perkasa Manunggal). Jurnal Administrasi Bisnis, 8(2).

Buchori, W. I., \& Djaelani, A. Q. (2017). Pengaruh Komitmen Organisasional, Stress Kerja, Kepuasan Kerja Terhadap Kinerja Karyawan. Jurnal IImiah Riset Manajemen, 6(07).

Dewi, I., \& Suwandana, I. (2016). Pengaruh Pemberdayaan Karyawan, Komitmen Organisasional Dan Kompensasi Finansial Terhadap Kepuasan Kerja Karyawan. E-Jurnal Manajemen Universitas Udayana, 5(4).

Eka S, D. S., Sunuharyo, B. S., \& Utami, H. N. (2016). Pengaruh Lingkungan Kerja Fisik Dan Non Fisik Terhadap Kepuasan Kerja Dan Kinerja Karyawan (Studi pada karyawan PT Telkom Indonesia Witel Jatim Selatan Malang). Jurnal Administrasi Bisnis, 40(1), 76-85.

Gunawan, A. W., \& Viyanita, O. (2012). Pemberdayaan Psikologi: Hubungannya dengan Kepuasan Kerja dan Komitmen Afektif. Media Riset Bisnis \& Manajemen, 12(1), 1-17.

Hendri, E. (2015). Pengaruh Lingkungan Kerja Fisik Dan Non Fisik Terhadap Kepuasan Kerja Karyawan Pada Pt Asuransi Wahana Tata Cabang Palembang. Jurnal Media Wahana Ekonomika.

Hasanuddin, R., \& Sjahruddin, H. (2017). The Structure of Emotional Intelligence, Spiritual Intelligence and Its Relationship with Work Enthusiasm and Auditor Performance. World Journal of Business and Management, 3(1), 67.

Ishak, A. P., Soegoto, A. S., \& Trang, I. (2016). Lingkungan Kerja, Pelatihan, Dan Pemberdayaan Pengaruhnya Terhadap Kinerja Karyawan Pada Pt. Asuransi Jiwasraya Manado. Jurnal Riset Ekonomi, Manajemen, Bisnis Dan Akuntansi, 4(2).

Lodjo, F. S. (2013). Pengaruh Pelatihan, Pemberdayaan Dan Efikasi Diri Terhadap Kepuasan Kerja. JURNAL RISET EKONOMI, MANAJEMEN, BISNIS DAN AKUNTANSI, 1(3).

Nursyamsi, I. (2017, January). Pengaruh Kepemimpinan, Pemberdayaan, dan Stres Kerja Terhadap Komitmen Organisasional serta dampaknya terhadap Kinerja Dosen. In Conference In Business, Accounting, And Management (CBAM) (Vol. 1, No. 2, pp. 405-423).

Ovi engga Arista, O. (2015). Pengaruh Persepsi Atas Corporate Social Responsbility Terhadap Kepuasan Kerja Dan Komitmen Organisasi (Survey Pada Hotel Bintang V Di Yogyakarta) (Doctoral dissertation, Fakultas Ekonomi).

Pratama, I. B. W., \& Sriathi, A. A. A. (2015). Pengaruh Stres Kerja Dan Pemberdayaan Terhadap Kepuasan Kerja Karyawan Di Prama Hotel. EJurnal Manajemen Universitas Udayana, 4(11).

Poniasih, N. L. G., \& Dewi, A. A. (2015). Pengaruh Motivasi Kerja, Komunikasi Dan Stres Kerja Terhadap Kepuasan Kerja Karyawan. E-Jurnal Manajemen Universitas Udayana, 4(6).

Putri, A. V., \& Ardana, I. K. (2016). Pengaruh Motivasi Dan Pemberdayaan Karyawan Terhadap Kinerja Karyawan PT. HD MOTOR 99 DENPASAR. EJurnal Manajemen Universitas Udayana, 5(11). 7272-7299

Sjahruddin, H. 1 E-Library STIE YPBUP Bongaya 2016. 
Issue 2 (November, 2017)

Sjahruddin, H. Konsekuensi Disiplin dan Pengalaman kerja pada Kinerja Aparatur Sipil Negara.

Sjahruddin, H. Dampak Karakteristik Pekerjaan dan Individu Pada Kepuasan Kerja Karyawan.

Sjahruddin, H., Vivi, M., \& Ahmad, A. (2014). Pengaruh Stres dan Lingkungan Kerja Non Fisik Terhadap Kinerja Karyawan Pada PT. Bumi Jasa Utama (Kallatransport) Makassar. E-Library STIE YPBUP Bongaya.

Sjahruddin, H. Kecerdasan Spiritual dan Emosional Sebagai Anteseden Kinerja Pegawai Kecerdasan Spiritual dan Emosional Sebagai Anteseden Kinerja Pegawai.

Styawahyuni, A., \& Yuniari, M. (2014). Pengaruh Pemberdayaan Karyawan dan Stress Kerja Terhadap Kepuasan Kerja Karyawan. E-Jurnal Manajemen Universitas Udayana, 3(6).

Suryadewi, P. C., Dunia, I. K., Erg, M., \& Suharsono, N. (2014). Pengaruh Pemberdayaan Karyawan Terhadap Kinerja Karyawan Pada Pt. Bali Segara Nusantara. Jurnal Jurusan Pendidikan Ekonomi, 4(1).

Saputro, A. B. (2014). Pengaruh Pemberdayaan Sumber Daya Manusia Terhadap Kinerja Pegawai Pada Komisi Pemilihan Umum Derah Kota Batu. Jurnal IImiah Mahasiswa FEB, 3(1).

Tukimin, S. E., \& MA, M. Pengaruh Stres Kerja Terhadap Kepuasan Kerja Pada Dinas Pertanian Sumatera Utara.

Widayanti, K. S., \& Sariyathi, N. K. (2016). Pengaruh Kepuasan Kerja, Pemberdayaan Karyawan, Dan Stres Kerja Terhadap Komitmen Organisasi Pada Cv. Akar Daya Mandiri. E-Jurnal Manajemen Universitas Udayana, 5(11). 